DOI 10.37882/2223-2982.2020.09-2.07

\title{
ОСОБЕННОСТИ КОНСТРУКЦИЙ С СЕНТЕНЦИАЛЬНЫМ AKTAHTOM В СОВРЕМЕННОМ ЯПОНСКОМ ЯЗЫКЕ
}

\section{FEATURES OF CONSTRUCTIONS WITH A SENTENTIAL ARGUMENT IN MODERN JAPANESE}

\section{E. Ermishina}

Summary: This article deals with the problem of representation of sentential arguments in modern Japanese. This problem is one of the most controversial in linguistics, since there is still no clear definition of the concept of "argument", in addition, there is no stable name for this linguistic phenomenon. This is due to some confusion about its content in academic circles. In turn, the definition of the content of this term depends on the outcome of the ongoing scientific discussion about arguments, the essence of which, in short, is whether to classify sentential arguments as semantic or purely syntactic constructions. The author adheres to the opinion, already voiced by some scientists, that semantic factors have priority in the construction of sentential arguments in Japanese, while morphosyntactic properties play the role of "serving" elements.

Keywords: sentential argument, Japanese language, semantics of the sentence, predicate, adjunct.
Ермишина Екатерина Сергеевна

Аспирант, Российский государственный гуманитарный университет

kyermishina@mail.ru

Аннотация: В данной статье рассматривается проблема репрезентации сентенциальных актантов в современном японском языке. Эта проблема является одной из наиболее дискуссионных в лингвистике, поскольку до сих пор нет четкого определения понятия «актант», кроме того, не имеется и стабильного наименования рассматриваемого лингвистического феномена. Это связано с некоторой путаницей относительно его содержания, существующей в академических кругах. В свою очередь, определение содержания данного термина зависит от исхода продолжающейся научной дискуссии об актантах, суть которой, вкратце, состоит в том, причислять ли сентенциальные актанты к семантическим или к чисто синтаксическим конструкциям. Автор придерживается мнения, уже озвученного частью ученых, что приоритет в конструировании сентенциальных актантов в японском языке имеют семантические факторы, в то время как морфосинтаксические свойства играют роль «обслуживающих» элементов.

Ключевые слова: сентенциальные актанты, японский язык, семантика предложения, предикат, сирконстант.

\section{Введение}

$\Pi$ онятие «актант» был введен в науку Л. Теньером, известным французским славистом, в 1959 году [12, c. 102]. И хотя дискуссии относительно семантического наполнения данного лингвистического феномена и его синтаксического выражения ведутся с тех пор, на данный момент термин еще не вполне определен. Пока в лингвистике нет даже стабильного именования этого феномена - в английском языке для его обозначения, например, принят термин argument. Нередко бывает и так, что этот термин используется для обозначения качественно разных понятий. Суть споров относительно содержания термина «актант» будет изложена во второй части нашей статьи, здесь ограничимся лишь постановкой проблемы.

С другой стороны, для исследователей-японистов актуальным остается вопрос типологизации японского языка и его лингвистических феноменов в общемировом контексте. В этой связи полипредикативные конструкции, которыми, по сути, являются предложения с сентенциальным актантом, обладают ключевым значением, поскольку представляют уникальный пример для построения функциональных типологических сравнений между разными языками. Уникальность такого рода конструкций объясняется демонстрацией нарушений прототипического соответствия между грамматической функцией конкретной единицы и ее грамматическим классом. В такой ситуации, на первый план выдвигается вопрос о семантическом наполнении синтаксических связей и того, каким образом семантика может влиять на синтаксис.

В связи с этим, возникает проблема определения функций предиката - как синтаксических, так и, в первую очередь, семантических, а также средств маркировки этого предиката, и сохранения или нивелирования его прототипических свойств.

Таким образом, данная статья представляет собой попытку анализа японских сентенциальных актантов в общетипологическом контексте. Это, на наш взгляд, позволяет должным образом идентифицировать многообразие функцией и выражений предиката. Основным ограничением в данной работе выступает уже упоминавшийся факт отсутствия точного определения термина «актант» и связанная с этим понятийная путаница, которая не позволяет стабилизировать терминологию.

Что касается сути нашего сообщения, то необходимо отметить, что основным исследовательским вопросом 
является соотношение смысла (семантики) и конструкций предложения (синтаксиса). Очевидно, что данная проблема является чрезвычайно объемной и многогранной, и данная статья представляет собой лишь малую часть возможных ее граней.

Основной гипотезой нашего исследования является положение, что проблемы, связанные с актантами, их статусом в современной лингвистике, в том числе - и с отсутствием исчерпывающего определения термина, могут быть решены только в контексте совмещения семантического и синтаксического аспектов рассмотрения, поскольку актант - это и есть полностью семантический обусловленный конструкт.

\section{Проблема сентеншиального актанта в языкознании}

В начале рассмотрения сразу обозначим область исследования. В современном языкознании принято разделять актанты на два типа: именные и сентенциальные (предикатные) актанты предикатов. Сравним:

1. (a) 彼は彼女の秘密を知っています - Он знает ее секрет

(6) 彼は彼女が昨年ヨーロッパの彼女の友達に 行ったことを知っています - Он знает, что в прошлом году она ездила к своему другу в Европу

В случае 1 (а) актант является именным, в случае 1 (б) - сентенциальным. Само понятие «сентенциальный» произошло от английского слова sentence, что само собой предполагает заполнение семантических слотов в такого рода примерах предложением, в данном примере это предложение «она ездила к своим друзьям в Европу». Интересно, что именные актанты по сравнению с сентенциальными изучаются намного более активно, что, скорее всего, связано с их более определенным синтаксическим статусом - они являются прототипическими заполнителями актантного слота. Однако, и это следует отметить отдельно: и именной, и сентенциальный актанты реализуют одинаковую семантическую функцию. Разница, таким образом, состоит лишь в детализации, которая, в свою очередь, определяет синтаксис.

На основании вышеприведенных примеров, можно дать следующее определение сентенциальному актанту: это конструкция, которая демонстрирует замещение валентности предиката не объектом, а ситуацией [11, с. 52]. В этом случае синтаксическая форма выражается наличием глагола и созданием отдельного предложения.

Изначально, однако, самим создателем данного термина, Теньером, под ним имелись в виду подлежащее, прямое дополнение и косвенное дополнение, - то есть те части предложения, которые так или иначе зависели от основного глагола. Теньер, при этом, игнорировал семантику подобного рода конструкций и подходил к проблеме исключительно с позиций синтаксиса.

Впервые о семантическом аспекте актантов заговорили представители Московской семантической школы [1] в рамках концепции «смысл-текст». После теории, аргументировавшей приоритет семантики перед синтаксисом определенной части актантов, данной проблеме стали посвящать свои работы и другие ученые. С 1990-х годов в языкознании стала развиваться такая идея, как «(лингвистическая) валентность», приверженцы которой также делали акцент на семантике, в то же время, фактически опираясь на синтаксический критерий, а именно: отделяя те актанты, которые относятся к непроизводным существительным, и те, которые относятся к отглагольным существительным, и причисляя к ним только последние $[6 ; 7 ; 10]$.

Таким образом, связи между семантическими отношениями и синтаксическими элементами предложения, выражающими их, были важной проблемой в рамках реляционной грамматики, лексико-функциональной грамматики, теории принципов и параметров и т. д.

Современные ученые (см., например, [9]) выделяют три основных типа актантов: семантический, глубинносинтаксический и поверхностно-синтаксический. Такое деление, по мнению авторов, обосновано зависимостью, а не избирательностью: в семантике, так же как и в синтаксисе, структуры, в которых появляются актанты, формируются маркированными отношениями зависимости между терминальными элементами.

\section{Особенности сентенциального актанта в японском языке}

Японский язык отображает широкий спектр конструкций связи предложений. Прежде чем перейти к анализу, возможно, будет полезно рассмотреть некоторые типологические свойства японского языка и кратко взглянуть на то, как реализуются различные типы конструкций связи предложений.

С точки зрения порядка слов, японский язык является типичным языком SOV, иллюстрирующим все обобщения типологии порядка слов Гринберга (1966). Что касается свободы порядка слов, то японский язык довольно ограничен.

Что касается грамматических отношений, японский язык является одновременно субъектно- и тематически ориентированным и может иметь конструкцию «множественного субъекта» [8]. Важно признать, что японский язык допускает прагматически обусловленное опущение аргумента NPs (включая как субъекты, так и объек- 
Виды предложений с сентенциальным актантом в современном японском языке [2]

Таблица 1.

\begin{tabular}{|c|c|}
\hline Вид сентенциального актанта & пы предиката \\
\hline Сентенциальный актант предиката & 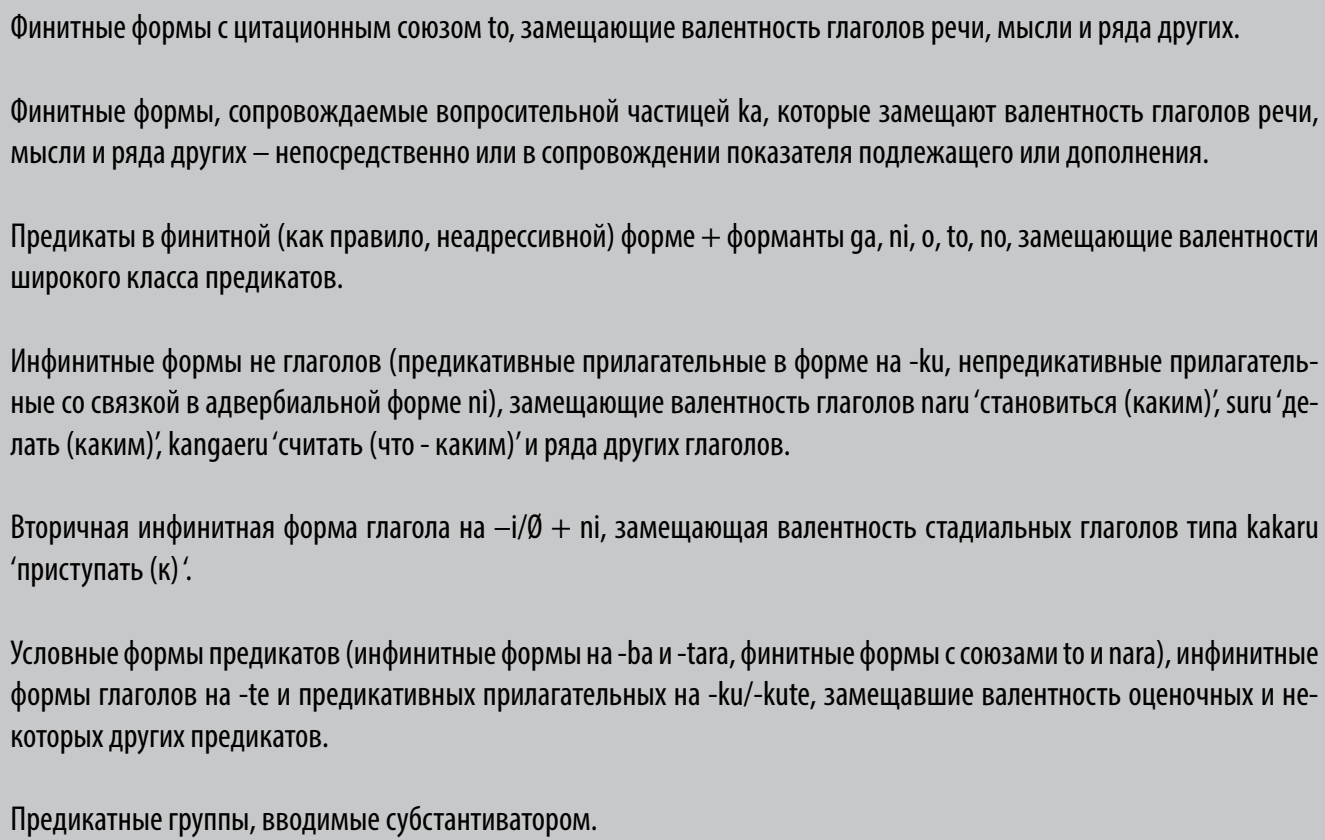 \\
\hline Сентенциальный актант имени & $\begin{array}{l}\text { Предикаты в финитной, так называемой «определительной» форме, непосредственно предшествующие своему син- } \\
\text { таксическому хозяину - именной группе - и заполняющие семантическую валентность этой именной группы: Каrera } \\
\text { wa hikooki ga tsuiraku shi-ta riyuu o kyuumei shi-ta. } \\
\text { Предикаты в финитной неадрессивной форме, вводимые служебным компонентом to yuu (цитационный союз + } \\
\text { глагол уuи 'говорить') }\end{array}$ \\
\hline
\end{tabular}

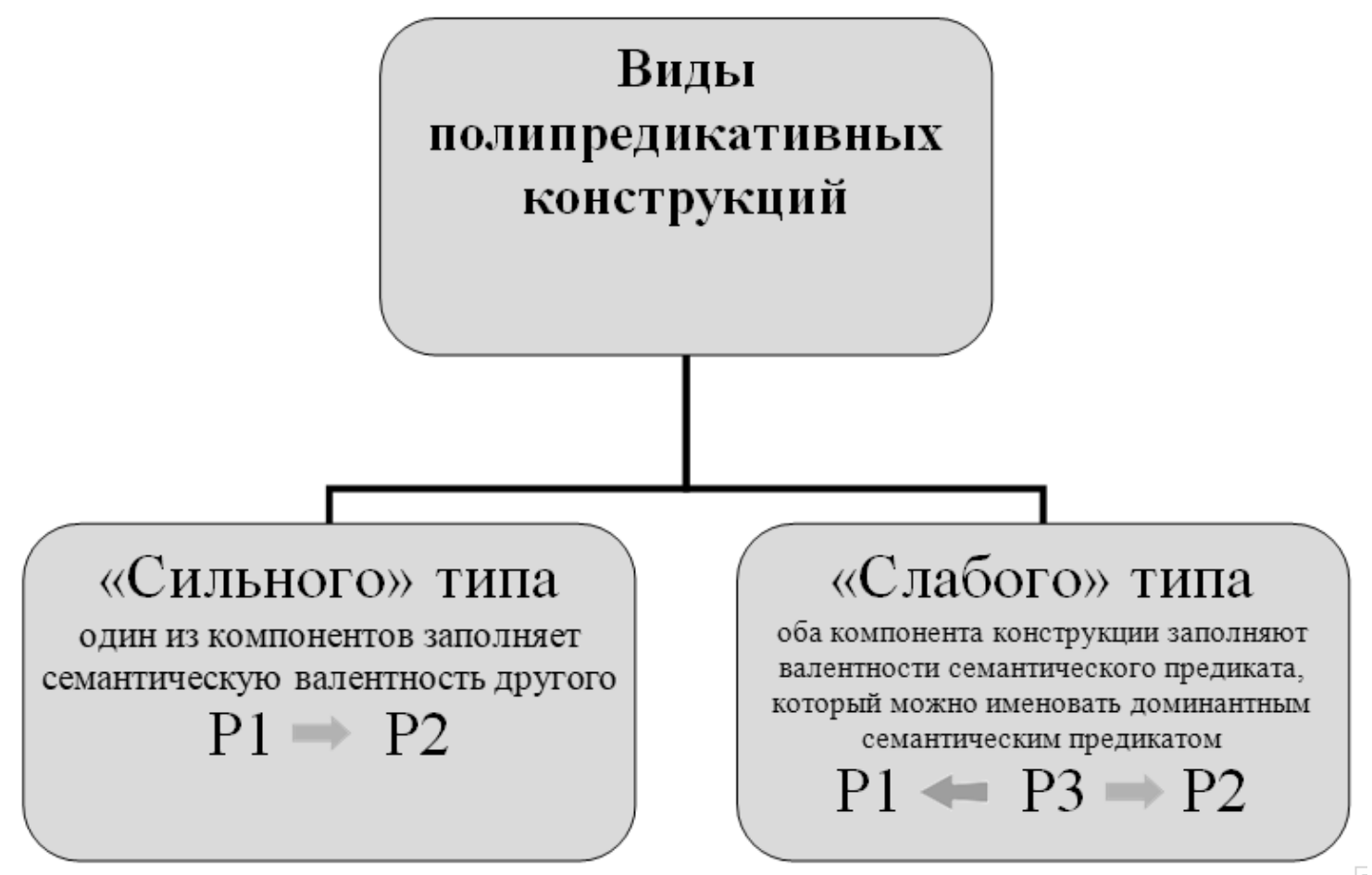

Рис. 1. Виды полипредикативных конструкций в японском языке 
ты).

В Таблице 1 указаны виды предложений с сентенциальным актантом в современном японском языке.

Отдельного рассмотрения, в контексте нашей темы, заслуживают также так называемые сентенциальные слова, в качестве которых многими японистами рассматриваются ряд имен (в частности, с модальным или временным значением), которые определяются как служебные слова: hazu, wake, hodo, и другие. Однако, в нашей статье данные случаи не рассматриваются.

Анализируя данные типы, можно сделать вывод о наличии в японском языке двух видов полипредикативных конструкций, критерием для выделения которых служит соотнесенность с семантической структурой, формирующей их основу:

Примером конструкций «сильного» типа являются предложения с сентенциальным актантом, примером конструкций «слабого» типа - предложения с сентенциальным сирконстантом.

В.И. Подлесская предлагает дополнительный критерий для разграничения сентенциального актанта от сентенциального определения, который можно назвать семантическим - он заключается определении совпадения семантического и синтаксического отношения между Р1 и Р2. Сентенциальный актант можно идентифицировать в том случае, если «синтаксически подчиненный компонент конструкции заполняет семантическую валентность своего хозяина» $[2,11]$ :

私は彼が明日来ることを知っています - Я знаю, 4mo он прuдеm завтра.

В обратном случае, будет иметь место сентенциальное определение.

Кроме того, полипредикативные конструкции, включающие в себя сентенциальный актант, можно назвать асимметричными конструкциями.

\section{Заключение}

На основании теоретического анализа, мы можем заключить, что японский язык обладает определенным механизмом, позволяющим разграничивать различные типы сентенциальных актантов. При этом, приоритетом служит именно семантика того или иного выражения то есть, основным критерием такого разграничения могут служить семантические классы предикатов. В такого рода конструкциях морфосинтаксические свойства отодвигаются на второй план и играют роль «обслуживающих» элементов.

\section{ЛИТЕРАТУРА}

1. Жолковский А.К. 0 правилах семантического анализа // Машинный перевод и прикладная лингвистика / Мгпиия им. М. Тореза. Вып. 8. М., 1964. C. 17-32.

2. Подлесская В.И. Сложное предложение и другие типы полипредикативных конструкций в современном японском языке: теория и типология. Дисс. на соискание уч. ст. д.ф.н. М., 1994.

3. Сердобольская Н.В. Семантика конструкций с сентенциальными актантами в кункинском варианте даргинского языка // https://iling-ran.ru/serdobolskaya/Serdobolskaya_qunqi_compl.pdf

4. Сердобольская Н.В. Синтаксический статус актантов зависимой нефинитной предикации. Дисс. на соискание уч. ст. к.ф.н. М., 2005.

5. Сердобольская Н.В., Мотлохов А.В. Семантика конструкций с сентенциальными актантами в адыгейском языке // Тестелец Я.Г. (отВ. ред.). Аспекты полисинтетизма: очерки по грамматике адыгейского языка. М.: РГГУ, 2009. С. 498-559.

6. Davis W., Dubinsky S. Objects and Other Subjects. Grammatical Functions, Functional Categories and Configurationality. Dordrecht etc.: Kluwer, 2001.

7. Lazard G. Définition des actants dans les langues européennes // Feuillet (ed.), 1998. Pp. 12-146.

8. Li C.N., Thompson S.A. Subject and topic: a new typology of language // Subject and Topic. New York: Academic Press, 1976. Pp. 457-489.

9. Mel'čuk I. Actants in Semantics and Syntax. I. Actants in Semantics // Linguistics, 42: 1, 2004, pp. 1-66.

10. Müller-Gotama F. Grammatical Relations. A Cross-Linguistic Perspective on their Syntax and Semantics. Berlin-New York: Mouton de Gruyter, 1994.

11. Noonan M. Complementation // Shopen (ed.), 1985, vol. 3, pp. 42-140.

12. Tesnière L. Éléments de syntaxe structurale. Paris: Klincksieck, 1959.

(c) Ермишина Екатерина Сергеевна (kyermishina@mail.ru).

Журнал «Современная наука: актуальные проблемы теории и практики» 